Camille Vilette*

\title{
CAMURE-9 \& ISMR-8: 9th International Symposium on Catalysis in Multiphase Reactors and 8th International Symposium on Multifunctional Reactors (Lyon, France, December 7-10, 2014)
}

DOI 10.1515/gps-2014-0036

\section{Context}

Twenty years after the first CAMURE meeting was launched in 1994, and after venues in Toulouse (France) 1998, Naples (Italy) 2000, Lausanne (Switzerland) 2002, Porto-Rose (Slovenia) 2005, Pune (India) 2007, Montreal (Canada) 2009 and Turku (Finland) 2011, the CAMURE series returns to Lyon. The merger of the two congress series CAMURE and ISMR was decided in 2005 for the Porto-Rose meeting and the so formed CAMURE-ISMR community is now proud to gather scientists working in the fields of catalysis, multiphase reactors and multifunctional reactors.

\section{Issues}

The 9th International Symposium on Catalysis in Multiphase Reactors (CAMURE-9) and the 8th International Symposium on Multifunctional Reactors (ISMR-8) is being organized by the University of Lyon, France, from December 7 to 102014 during the Festival of Lights of Lyon.

\section{Organizing committee}

Chairman: Claude De Bellefon, University of Lyon, CPE Lyon \& CNRS

Pascal Fongarland, University of Lyon, IRCELyon

Régis Philippe, University of Lyon, CPE Lyon \& CNRS

*Corresponding author: Camille Vilette, Lyon Ingénierie Projets, 43 bd du 11 novembre 1918, Villeurbanne 69100, France,

e-mail: camille.vilette@lip-lyon1.fr
Pascal Pitiot, Solvay, Lyon

Philippe Marion, Solvay, Lyon.

\section{CAMURE-9 \& ISMR-8, the European scientific forum}

The CAMURE-ISMR series offers an interdisciplinary forum for discussing the progress of research in the design of novel catalysts, catalytic processes and reactors, chemical kinetics, heat and mass transfer, hydrodynamics and reactor modeling. The scope of the conference is to provide and discuss the latest information on the science and technology of catalysis, catalytic processes and reaction engineering and also aims at emphasizing the specificity of coupling catalysis with reactor design, including molecular and bio catalysis.

\section{CAMURE-9 \& ISMR-8, the sustainable challenge}

Today's research in the fields of Catalysis and Reactors Engineering must also apply to a more sustainable future and CAMURE-9 \& ISMR-8 will also address the use and design of multiphase and multifunctional reactors to the selected challenges of bio-based chemicals, $\mathrm{CO}_{2}$ capture, storage and uses, energy conversion and storage and catalysis for natural gas conversion.

\section{Scientific program}

The conference will act as an international forum for the exchange of ideas on recent scientific and technical issues 
among researches and engineers from both industrial and academic sectors.

\section{Key aspects}

- Alternative energy input

- Catalyst handling in multiphase reactors, including catalytic coating, catalyst flowing

- Catalytic reactions in multiphase structured reactors

- Catalytic reactors with non-conventional solvents

- Coupling separation and catalysis

- High-shear, high-gravity systems

- Hydrodynamics, mass and heat transfers in structured reactors

- Impact of heat and mass transfer on catalytic reactions

- Intensification of multiphase catalytic processes

- Mastering, understanding and making use of transient processes in catalytic reactors

- Multifunctional devices: smart integration of mixing, heat transfer, reaction, separation

- Multiphase flow in micro/milli reactors and separators

- Multiphase reactors as applied for bio-processes

- Novel process windows in multiphase reactors

- Online reaction monitoring and catalyst characterization.

\section{Venue}

\section{Valpre}

A very nice arranged space favoring work, the exchange of ideas and relaxation a 320 square meter adaptable area including 20 modular meeting places - all with natural light. Lyon is a real European crossroads. Anchored in history, Valpre has become a key figure in the tourism business in Lyon. Ideally located in a 15-acre wooded park, close to Lyon, this unconventional Convention Center is a perfect compromise between work and relaxation. The University of Lyon is the second biggest scientific cluster in France.

\section{An amazing context...}
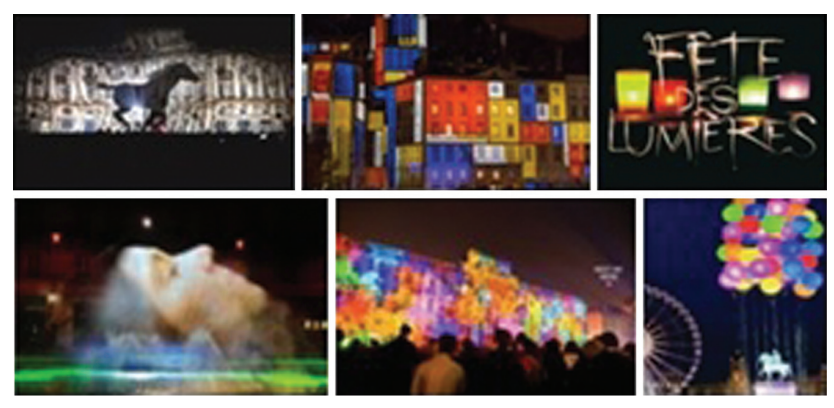

The CAMURE-9 \& ISMR-8 conference will take place at the same time as the famous Festival of Lights. Surprise surprise! Is this by chance, or are the Organizing Committee giving you this amazing opportunity to split your trip between the sciences and magic?

The Festival of Lights broadcasts Lyon's heritage during 4 days of pure magic. The city definitely lives up to its title as the city of lights which everyone enjoys. Designers from all over the world partake in the wonderful event. video, music and sound effects are used to accompany the vibrant images dotted around the city.

The exceptional spectacle showcases the city at its best and incorporates buildings, rivers and parks. Those attending will have the chance to cruise on the Rhône and Saône rivers, in the heart of the lights, during a special evening!

Let us kill two birds with one stone... CAMURE-ISMR 2014 participants will share their scientific knowledge during the day and share the world-renowned lights of the festival at night.

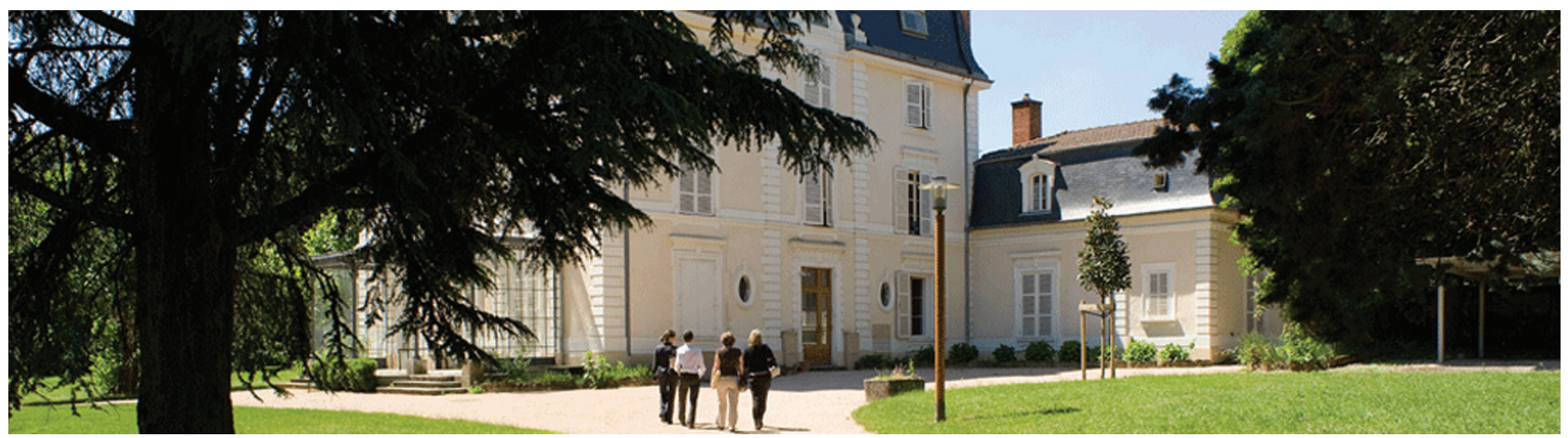




\section{Contact}

Domitille Tricou

Conference Management

E-mail: contact@camure2014.fr

www.camure2014.fr

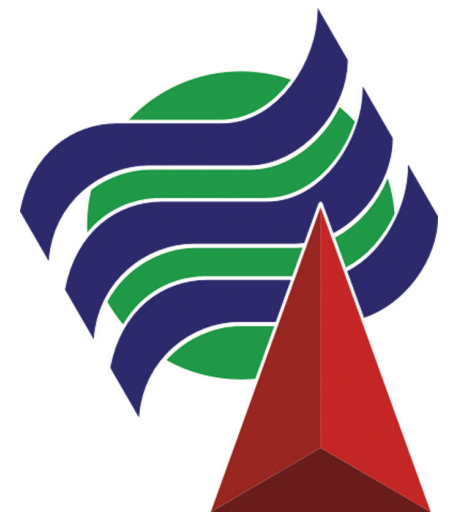

